\title{
ANÁLISE DA EDUCAÇÃO AMBIENTAL NOS ÓRGÃOS PÚBLICOS AMBIENTAIS DOS MUNICÍPIOS DE ADAMANTINA E DRACENA - SP.
}

\author{
Cristina Toyoko Hashimoto ${ }^{1}$
}

\author{
Angélica Góis Morales ${ }^{2}$
}

\begin{abstract}
RESUMO
O presente trabalho teve como objetivos mapear os órgãos públicos que estão relacionados com a temática ambiental nos municípios de Adamantina e Dracena - SP, localizados na bacia hidrográfica Peixe-Aguapeí, no extremo oeste paulista, identificar a presença ou ausência de programas, projetos e/ou práticas de educação ambiental que estão sendo desenvolvidos pelos órgãos públicos estudados, e verificar a concepção de educação ambiental e de meio ambiente dos órgãos públicos estudados diante da presença de programas, projetos e/ou práticas de educação ambiental. Para isso, realizou-se uma pesquisa qualitativa com abordagem exploratória com o auxílio da pesquisa de campo nos municípios em estudo. Por meio de um questionário semiestruturado para os órgãos públicos, foi possível verificar que os mesmos desenvolvem atividades relacionadas a temática ambiental, contudo a educação ambiental ainda se reflete em ações pontuais.
\end{abstract}

PALAVRAS-CHAVE: Educação ambiental. Meio Ambiente. Órgãos Públicos.

\section{THE DIMENSION OF ENVIRONMENTAL EDUCATION IN PUBLIC AGENCIES IN THE CITY OF ADAMANTINA AND DRACENA - SP}

\footnotetext{
ABSTRACT

The present study aimed to map the public agencies that are related to environmental issues in the city of

${ }^{1}$ Discente, bolsista do Programa Institucional de Bolsas de Iniciação Científica (PIBIC), Univ. Estadual Paulista "Júlio de Mesquita Filho" (UNESP), Câmpus Experimental de Tupã. crishashimoto@tupa.unesp.br.

${ }_{2}^{2}$ Doutora em Meio Ambiente e Desenvolvimento (UFPR), Univ. Estadual Paulista "Júlio de Mesquita Filho" (UNESP), Câmpus Experimental de Tupã. Docente do curso de Administração. angélica@tupa.unesp.br
} 
Adamantina and Dracena - SP, located in Peixe-Aguapeí watershed, in the extreme west of São Paulo State, identify the presence or absence of programs, projects and/or practices of environmental education that are being developed by the studies public agencies, and verifying of the conception of environmental education and environment assumed by public agencies studied with the presence of programs, projects and / or environmental education practices. For this, we carried out a qualitative research with exploratory approach end the aid of field research in the cities under study. Through a semi-structured questionnaire for public agencies, we found that they develop activities related to environmental issues, but environmental education is still reflected in specific actions.

KEY-WORDS: Environmental Education. Environment. public agencies.

\section{ANÁLISIS DE LA EDUCACIÓN AMBIENTAL EN LAS ORGANIZACIONES PÚBLICAS EN LOS MUNICIPIOS DE ADAMANTINA Y DRACENA - SP.}

\section{RESUMEN}

Este estudio tuvo como objetivo mapear los organismos públicos que se relacionan con las cuestiones ambientales en los municipios de Adamantina y Dracena - SP, que se encuentra en la cuenca de los pescados Aguapeí, en el extremo oeste de São Paulo, identificar la presencia o ausencia de programas, proyectos y / o prácticas de educación ambiental que se están desarrollando por los organismos públicos estudiados, y verificar el diseño de la educación ambiental y los organismos públicos ambientales estudiados en la presencia de programas, proyectos y / o prácticas de educación ambiental. Para ello, llevamos a cabo una investigación cualitativa con enfoque exploratorio con la ayuda de la investigación de campo en la ciudad bajo estudio. A través de un cuestionario semi-estructurado de los organismos públicos, encontramos que desarrollan actividades relacionadas con las cuestiones ambientales, pero la educación ambiental todavía se refleja en acciones concretas.

PALABRAS CLAVE: Educación Ambiental. Medio Ambiente. Organismos Públicos.

\section{INTRODUÇÃO}

O tema educação ambiental tem sido destaque nos últimos anos, no meio acadêmico, ensino fundamental e médio, e principalmente no meio empresarial. Com o rápido crescimento da população, e o consequente aumento do consumo, tem gerado uma maior preocupação com a preservação e conservação do meio ambiente, e a educação ambiental entra neste contexto como um dos principais instrumentos de sensibilização e conscientização na sociedade. 
A educação ambiental trata-se de uma parte importante da educação fundamental, fazendo parte da esfera de interações que, por sua vez, fazem parte do desenvolvimento pessoal e social. A educação ambiental tem o papel de induzir a dinâmicas sociais, podendo iniciar-se em comunidades e posteriormente chegando a atingir redes mais amplas, permitindo abordagem colaborativa, difusão de informações, compreensão de problemas e soluções sobre a realidade socioambiental. (SAUVÉ, 2005)

Segundo a Lei n 9.795, de 27 de abril de 1999, capítulo 1, Art. 1ํ do Programa Nacional de Educação Ambiental - ProNEA, a educação ambiental entende - se por:

Entende-se por educação ambiental os processos por meio dos quais o indivíduo e a coletividade constroem valores sociais, conhecimentos, habilidades, atitudes e competências voltadas para a conservação do meio ambiente, bem de uso comum do povo, essencial à sadia qualidade de vida e sua sustentabilidade. (BRASIL, 2005, p.65)

Diante da preocupação com as questões ambientais, muitas organizações têm adotado medidas para diminuir os impactos causados sobre o meio ambiente, tais como programas, projetos e a adoção de gestão ambiental. E assim, a educação ambiental vem adentrando como um dos principais instrumentos que levam a um processo de reflexão ao ambiente das organizações.

A educação ambiental é uma dimensão desenvolvida de maneira recente nos órgãos públicos e sua inserção é crescente, principalmente após a Conferência das Nações Unidas sobre o Meio Ambiente e Desenvolvimento, realizada no Rio de Janeiro no ano de 1992. Dessa Conferência, resultam a Carta da Terra e a Agenda 21, que propõe compromissos ambientais a serem adotados pelos países participantes, com ênfase no planejamento socioambiental levando-se em consideração o princípio da sustentabilidade. No entanto, desde a conferência até os dias de hoje, poucas ações se desenvolveram diante do que foi proposto durante a conferência e na Agenda 21 (ADAMS apud ADAMS e GEHLEN, 2008).

Diante dos problemas ambientais enfrentados pela sociedade atualmente, o Estado deve assumir um comportamento ativo com relação a conservação e 
preservação do meio ambiente, e envolvendo os diversos setores da sociedade (FARIA et al, 2013).

A educação ambiental insere-se nas políticas públicas como uma ação organizada pelo Estado, pautada pelo ProNEA e articulada pelos Ministérios do Meio Ambiente (MMA) e da Educação (MEC) sob a Coordenação Geral de Educação Ambiental, as quais são responsáveis pela implantação de programas e projetos junto às redes públicas de ensino, unidades de conservação, prefeituras municipais, empresas, sindicatos, movimentos sociais, comitês de bacia hidrográfica, assentamentos de reforma agrária, entre outros parceiros (SORRENTINO et al, 2005).

Como destaca a Política Nacional de Educação Ambiental:

Art. 3o Como parte do processo educativo mais amplo, todos têm direito à educação ambiental, incumbindo:

I - ao Poder Público, nos termos dos artigos 205 e 225 da Constituição Federal, definir políticas públicas que incorporem a dimensão ambiental (...); II - às instituições educativas, promover a educação ambiental de maneira integrada aos programas educacionais que desenvolvem; III - aos órgãos integrantes do Sistema Nacional de Meio Ambiente - SISNAMA, promover ações de educação ambiental integradas aos programas de conservação, recuperação e melhoria do meio ambiente (...) $\mathrm{V}$ - às empresas, entidades de classe, instituições públicas e privadas, promover programas destinados à capacitação dos trabalhadores, visando à melhoria e ao controle efetivo sobre o ambiente de trabalho, bem como sobre as repercussões do processo produtivo no meio ambiente (...) (BRASIL, 1999).

Assim, a educação ambiental, como um direito a todos, é um dos principais mediadores da gestão ambiental, em que os agentes públicos, orientados pelo ProNEA, são responsáveis pela construção, implementação de políticas públicas e ações que possibilitem solucionar questões estruturais, levando a sustentabilidade socioambiental (BRASIL, 2005). Portanto, esse trabalho, apresenta como pergunta norteadora: Qual a abordagem da educação ambiental e o enfoque da política ambiental, inseridos na gestão dos órgãos públicos relacionados à temática ambiental nos municípios de Adamantina e Dracena?

Diante da questão norteadora, dessa pesquisa, o objetivo geral foi identificar os órgãos públicos que atuam na área ambiental, localizados nos municípios sede de 
Adamantina e Dracena - SP, que fazem parte da microrregião do Peixe-Aguapeí, pertencente a região da Alta Paulista.

Para tanto, os objetivo específicos foram: a) identificação dos órgãos públicos relacionados com a temática ambiental nos municípios de Adamantina e Dracena SP, situados no extremo oeste paulista; b) identificar a presença ou ausência de programas, projetos e/ou práticas de educação ambiental que estão sendo desenvolvidos pelos órgãos públicos estudados; e c) identificar as diversas concepções de educação ambiental e de meio ambiente dos órgãos públicos estudados diante da presença de programas, projetos e/ou práticas de educação ambiental.

\section{METODOLOGIA}

Essa pesquisa foi de cunho qualitativo, por ter os interesses centrais direcionados para o significado conferido aos atores sociais e o processo pelo qual as ações desses são desenvolvidas (MYNAIO, 1996; TRIVIÑOS, 1987).

Para essa pesquisa, delimitaram-se como casos a serem estudados: órgãos públicos afins, que atuam direta/indiretamente na área ambiental, nos municípios de Adamantina e Dracena. Desconsiderou-se para esta pesquisa os órgãos públicos mistos.

Assim, escolheu-se trabalhar com multicasos, de acordo com o diagnóstico levantado na pesquisa, delimitando-se a área de abrangência dos municípios de Adamantina e Dracena, localizado na microrregião do espigão divisor Peixe-Aguapeí do extremo oeste paulista.

\section{Histórico do município de Adamantina - SP}

A história do município de Adamantina está associada a Companhia de Agricultura, Imigração e Colonização (CAIC) que, em 1937, reiniciou o processo de colonização da região, dando continuidade ao processo que já havia iniciado no 
Estado, e na mesma época iniciou-se a abertura de estradas e a venda de terras (PREFEITURA DE ADAMANTINA, 2014).

A fundação do município de Adamantina data do dia 24 de dezembro de 1948, e o crescimento da cidade estão associados ao surto cafeeiro e a chegada da ferrovia como ponto final (PREFEITURA DE ADAMANTINA, 2014).

O município de Adamantina atualmente, segundo dados do IBGE (2013), conta com aproximadamente 33.797 habitantes, e possui sua economia voltada predominantemente para a indústria, serviços e agropecuária.

\section{Histórico do município de Dracena - SP}

Atualmente o município de Dracena é constituído de três distritos, Dracena, Jamaica e Jaciporã e foi elevada a categoria de município em dezembro de 1953 (IBGE, 2013). Dracena, cujo nome é a designação de uma planta ornamental, foi fundada por Irio Spinardi, João Vandramini, Virgílio e Florêncio Fioravante, em 8 de dezembro 1945 (CÂMARA MUNICIPAL DE DRACENA, 2014).

A economia do município é predominantemente voltada para o setor de serviços, indústria e agropecuária, e segundo dados do IBGE, censo de 2013, Dracena possui aproximadamente 43.258 habitantes.

\section{Procedimentos e instrumentos de coleta de dados}

Diante da metodologia adotada, a pesquisa se desenvolveu por três fases. São elas:

a) Exploratória: que constituiu na imersão do problema oportunizando uma visão geral do problema e aprimoramento da literatura. Para tanto, foi adotado nessa fase a pesquisa bibliográfica e documental. A pesquisa documental foi realizada por meio da pesquisa de documentos disponíveis em sites online das instituições públicas, bem como outros sites da internet, e também com documentos coletados durante a pesquisa de campo. 
b) Descritiva: nessa fase foi realizado um levantamento dos órgãos públicos nos municípios, bem como o mapeamento da presença ou ausência de educação ambiental, por meio da listagem de todos os órgãos públicos de cada município, e posteriormente a identificação dos órgãos relacionados a temática ambiental. A listagem dos órgãos públicos foi realizada por meio de consultas a sites da internet, sites institucionais dos próprios órgãos públicos e site das prefeituras locais.

c) Pesquisa de campo: essa fase constituiu em conhecer os órgãos públicos que possuem projetos e/ou programas de educação ambiental que atuam nos municípios, por meio de visitas técnicas para o estabelecimento de contatos com as equipes e/ou profissional que estão envolvidos no processo de educação ambiental, aplicação de questionário e solicitação de documentos para a analise como a política ambiental, programas e projetos ligados a educação ambiental. Assim, nessa fase, adotou-se a técnica de questionário com perguntas fechadas e abertas para coleta de dados a fim de atender os objetivos propostos dessa pesquisa.

\section{RESULTADOS}

Como resultados da pesquisa, foram realizados o mapeamento dos órgãos públicos de Adamantina e Dracena - SP, a pesquisa de campo, e a aplicação do questionário.

Inicialmente, para o levantamento dos órgãos públicos e o mapeamento dos mesmos, foram realizadas pesquisas bibliográficas sobre o que são órgãos públicos, posteriormente, foram listados os órgãos presentes na cidade sede a ser pesquisada. Para a realização do mapeamento, também foram realizadas pesquisas dos endereços de cada órgão público, por meio de sites institucionais dos próprios órgãos, sites das prefeituras locais e outros sites de busca. E por fim foi realizado o recorte dos órgãos públicos ambientais, aqueles que estão relacionados com as questões ambientais em cada município.

Com relação a pesquisa de campo, foram realizadas visitas técnicas, e encontraram-se algumas dificuldades, quanto ao acesso aos órgãos públicos, devido 
a localização dos endereços, visto que o endereço de muitos órgãos encontram-se desatualizados nos sites institucionais, e os seus números de contato.

Além dos dados desatualizados, por parte de alguns órgãos públicos, encontraram-se dificuldades quanto ao agendamento de visitas e ao acesso as informações nos órgãos públicos, devido a burocracia e a escassez de informações fornecidas pelos próprios.

Na primeira fase, foram mapeados nove órgãos públicos, dos quais cinco estão ligados as questões ambientais no município de Adamantina e três no município de Dracena.

As informações utilizadas nesta pesquisa foram obtidas por meio de um questionário aplicado aos colaboradores responsáveis pela área ambiental de cada órgão público, e também por meio da pesquisa de campo.

A seguir, serão analisados os resultados obtidos dos órgãos participantes dos municípios de Adamantina e Dracena.

Para adequação dos órgãos públicos participantes desta pesquisa, adotaramse as nomenclaturas: OPA1, OPA2, OPA3, OPA4, OPA5, OPD1, OPD2 e OPD3, conforme apresentado no Quadro 1. 


\section{Quadro 1: Órgãos Públicos que atuam na área ambiental do município de Adamantina e Dracena.}

\begin{tabular}{|c|c|c|}
\hline \multicolumn{3}{|c|}{ Órgãos Públicos - Adamantina e Dracena } \\
\hline Órgãos Públicos & Ramo & Caracterização \\
\hline OPA1 & Educação & $\begin{array}{l}\text { Atua na supervisão e apoio as } \\
\text { instituições de ensino no âmbito regional. }\end{array}$ \\
\hline OPA2 & Extensão Rural & $\begin{array}{c}\text { Responsável pelo apoio e assistência técnica } \\
\text { aos produtores rurais } \\
\text { da região em que atua. }\end{array}$ \\
\hline OPA3 & Educação & $\begin{array}{l}\text { Atua na coordenação, promoção das atividades } \\
\text { educacionais do Município, na supervisão e } \\
\text { fiscalização das escolas do município. }\end{array}$ \\
\hline OPA4 & Ambiental & $\begin{array}{l}\text { Supervisão, inspeção e controle das ações } \\
\text { ambientais realizadas no município. }\end{array}$ \\
\hline OPA5 & $\begin{array}{l}\text { Pesquisa Científica } \\
\text { ligada ao } \\
\text { Agronegócio }\end{array}$ & $\begin{array}{c}\text { Coordenar e gerenciar as atividades de ciência e } \\
\text { tecnologia voltadas para } \\
\text { o agronegócio. }\end{array}$ \\
\hline OPD1 & Educação & $\begin{array}{l}\text { Atua na coordenação, promoção das atividades } \\
\text { educacionais do Município, na supervisão e } \\
\text { fiscalização das escolas do município. }\end{array}$ \\
\hline OPD2 & Extensão Rural & $\begin{array}{c}\text { Responsável pelo apoio e assistência técnica } \\
\text { aos produtores rurais } \\
\text { da região em que atua. }\end{array}$ \\
\hline OPD3 & Ambiental & $\begin{array}{l}\text { Supervisão, inspeção e controle das ações } \\
\text { ambientais realizadas no município. }\end{array}$ \\
\hline
\end{tabular}

Fonte: Elaborado pelos autores com base nos dados coletados da pesquisa (2014).

O quadro 1 mostra a relação dos órgãos públicos que participaram da pesquisa, apresentando o ramo de atuação e a caracterização do órgão. Nota-se que os órgãos pesquisados estão distribuídos nas áreas da educação (OPA1, OPA3 e OPD1), ambiental (OPA4 e OPD3), extensão rural (OPA2 e OPD2) e pesquisa (OPA5), mostrando que a questão ambiental é abordada, de alguma forma, em diversos tipos de órgãos públicos. 
Quadro 2: 0 que é a Educação Ambiental pra você?.

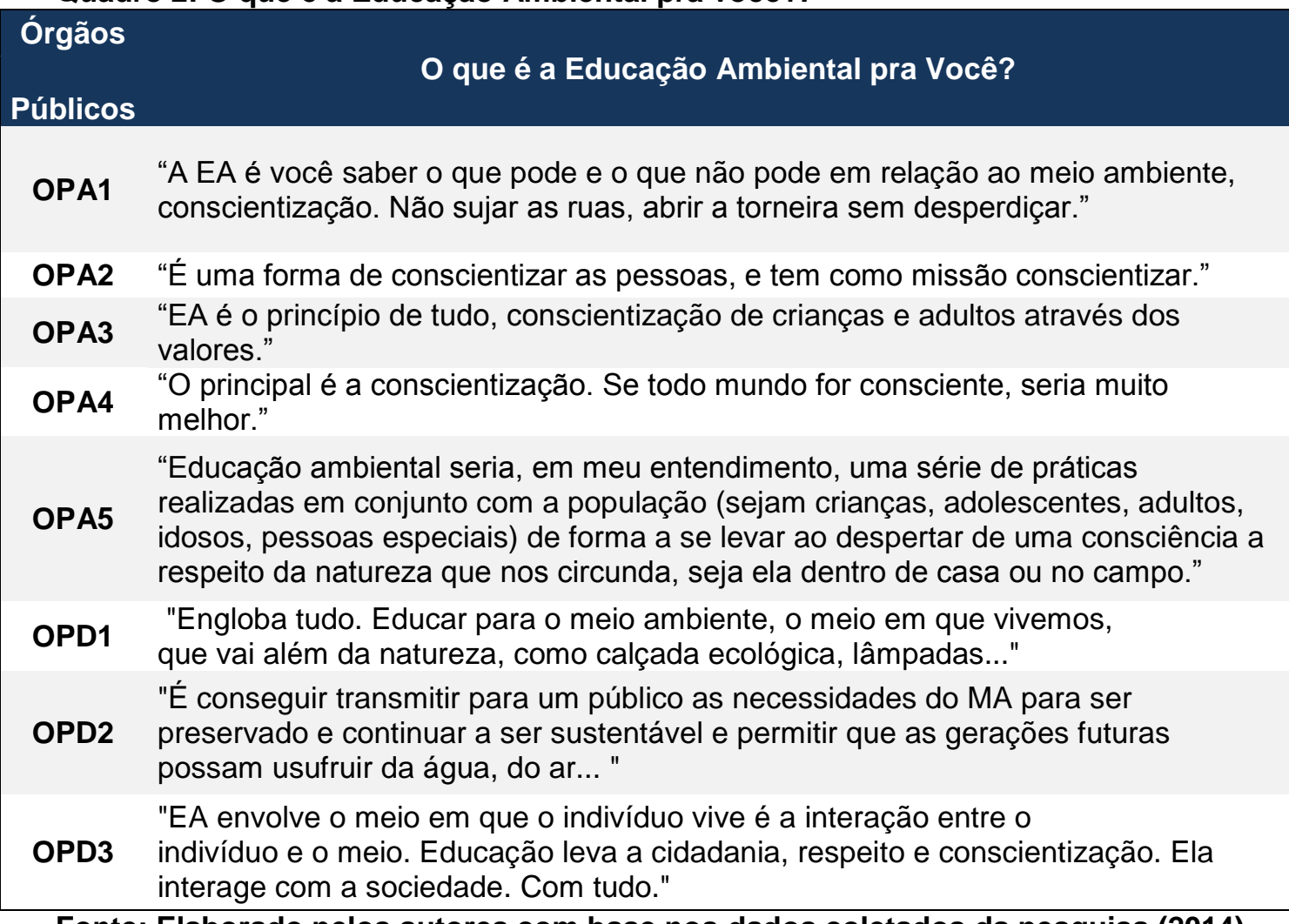

Fonte: Elaborado pelos autores com base nos dados coletados da pesquisa (2014).

De acordo com o quadro 2, os colaboradores que participaram da pesquisa, responsáveis pela área ambiental do seu órgão, quando indagados sobre o que é a educação ambiental na concepção de cada um deles, todos descreveram ter uma visão voltada para a conscientização das pessoas, mostrando que os colaboradores tem consciência de que a educação ambiental é um processo constante de conscientização.

Através da pesquisa, os órgãos públicos mostraram que atuam na área da educação ambiental, em sua maioria, por meio da realização de atividades, e algumas realizam projetos e programas voltados para a área ambiental, como podemos observar no quadro 3 : 
Quadro 3: Formas de trabalho desenvolvido pelos órgãos públicos.

\begin{tabular}{|c|c|c|c|c|}
\hline \multicolumn{5}{|c|}{$\begin{array}{l}\text { Como é trabalhada a educação ambiental } \\
\text { no seu órgão público? (pode ser assinalada mais de uma opção) }\end{array}$} \\
\hline $\begin{array}{l}\text { Órgãos } \\
\text { Públicos }\end{array}$ & Programas & Projetos & Atividades & Outra forma. Qual? \\
\hline OPA1 & $\mathrm{X}$ & $x$ & $x$ & \\
\hline OPA2 & & & $x$ & \\
\hline OPA3 & $x$ & $x$ & $x$ & \\
\hline OPA4 & & $x$ & $x$ & \\
\hline OPA5 & & & $x$ & \\
\hline OPD1 & $x$ & $x$ & $x$ & \\
\hline OPD2 & $x$ & $x$ & $x$ & \\
\hline OPD3 & $x$ & $x$ & $x$ & Metas/Diretrizes \\
\hline
\end{tabular}

Fonte: Elaborada pelos autores com base nos dados coletados da pesquisa (2014).

De acordo com os dados coletados na pesquisa, os órgãos públicos de Adamantina realizam atividades pontuais, principalmente atividades voltadas para 0 público do ensino fundamental e médio, tais como visitas e palestras, como relata o colaborador do órgão OPA3 "São realizados desde passeios, visitas a hortas comunitárias, visitas a usina de lixo, reflorestamento realizado pelas crianças nas margens do rio, e a coleta de lixo nas margens do rio.", e o colaborador do órgão OPA5: "Recebemos visitas agendadas de escolas municipais onde realizamos palestras temas ligados ao uso da água, a importância das florestas, ciclo da água, entre outros. E, eventualmente, realizamos plantio de mudas com as crianças ao mesmo tempo em que focamos a importância da biodiversidade para a manutenção da natureza.". Essas atividades mostram que há certa preocupação com a conscientização das crianças, com relação as questões ambientais.

Em Dracena, constatou-se que os órgãos públicos realizam projetos, atividades e programas, que são voltados principalmente para as escolas, como por exemplo o projeto "Vamos colocar a mão na lata" desenvolvido pelo órgão OPD1, em que segundo o colaborador responsável "Este projeto é baseado no recolhimento de lacres de latas de alumínio (ex.: latas de refrigerante), assim, a cada $X$ lacres, é revertida pela troca por cadeiras de rodas.", e o "Programa Sustentabilidade" que também é desenvolvido nas escolas e consiste no estimulo ao desenvolvimento de textos, figuras, em que uma das premiações é a publicação da figura premiada na 
capa de um livro do programa, além de outras premiações realizadas ao final de cada ano. Constatou-se também que são realizadas atividades e projetos de coleta seletiva em Dracena, e também projetos de Ecopontos, que de acordo com o colaborador do órgão OPD3, os Ecopontos são lugares apropriados para o descarte de galhos, folhas, resíduos de construção civil, e lixo de limpeza pública.

Os projetos e programas, desenvolvidos pelos órgãos públicos nos municípios de Adamantina e Dracena, são voltados para a comunidade local, tais como os programas voltados para a coleta seletiva do lixo e a coleta do óleo usado para a reciclagem. Essas ações praticadas pelos órgãos públicos, segundo o colaborador do órgão OPA4, são motivadas principalmente pelo Programa Município Verde Azul, da qual Adamantina e Dracena participam e ocupam respectivamente, segundo o ranking de 2013 do Município Verde Azul, as posições $42^{\mathrm{a}}$ e $38^{\mathrm{a}}$ entre os 587 municípios que compõe esse ranking.

O Programa Município Verde Azul - PMVA, programa da Secretaria Municipal de Meio Ambiente do Estado de São Paulo, visa o estímulo e a capacitação das Prefeituras para a implementação e desenvolvimento de uma agenda ambiental, e também visa o desenvolvimento e aplicação de Planos Ambientais municipais, com o objetivo de melhorar as condições de vida da população (SECRETARIA DO MEIO AMBIENTE, 2013).

Apesar do município de Adamantina participar do Programa Município Verde Azul, os órgãos OPA2 e OPA5, afirmaram que não possuem uma política ambiental no órgão público, os órgãos OPA1 e OPA3 possuem políticas ambientais no órgão com enfoque educacional e a segunda com enfoque na conscientização e educação ambiental, e somente o órgão OPA4 afirmou ter como política ambiental no órgão o PMVA. Com isso, nota-se que não há um diálogo entre os órgãos públicos no município de adamantina, e que não seguem as mesmas diretrizes apesar de estarem no mesmo município.

No município de Dracena, os órgãos públicos tem seus trabalhos de educação ambiental baseados na política ambiental do município, além das políticas federais e estaduais, como por exemplo, o órgão OPD3 que segue a política de educação ambiental do município, a Política Nacional de Resíduos Sólidos, CONAMA, 
FEHIDRO e o código florestal. No entanto, nenhum deles afirmou desenvolver seus trabalhos de educação ambiental baseados no ProNEA e na Política Nacional de Educação Ambiental (lei 9795/99).

As atividades, projetos e programas realizados no município de Adamantina pelos órgãos participantes, também não são baseados nas políticas públicas, como 0 ProNEA, com exceção do órgão OPA3. O órgão OPA1 relatou ter suas ações baseadas na Secretaria do Estado, o órgão OPA4 tem suas atividades baseadas no Plano de Gerenciamento de Resíduos Sólidos, já os órgãos OPA2 e OPA5 afirmaram que suas atividades não possuem embasamento em nenhuma política pública.

Apesar das diferenças, com relação ao enfoque e ao embasamento para o desenvolvimento das ações nos órgãos participantes da pesquisa, todas as atividades estão relacionadas ou atuam na Bacia Hidrográfica Peixe-Aguapeí, e todos os órgãos afirmaram que $o$ impacto dessas ações são positivas, aumentando a conscientização das pessoas envolvidas nessas atividades, projetos e programas.

As parcerias entre os órgãos públicos e as empresas para a realização das atividades, projetos e programas, também estão presentes e esse tipo de parceria tem contribuído para a difusão da educação ambiental, ainda que pequena.

A pesquisa também mostrou como é a visão dos colaboradores em relação as concepções de Educação Ambiental e Meio Ambiente, em que foram colocadas três tipos de definições (Naturalista, Antropocêntrica e Sistêmica) para cada um dos temas, com o nível de concordância contendo cinco níveis: 1- Discordo totalmente; 2Discordo parcialmente; 3-Indiferente; 4- Concordo parcialmente e 5- Concordo totalmente que foram assinaladas de acordo com a opinião de cada colaborador. 
Gráfico 1: Visão sobre a concepção de Educação Ambiental.

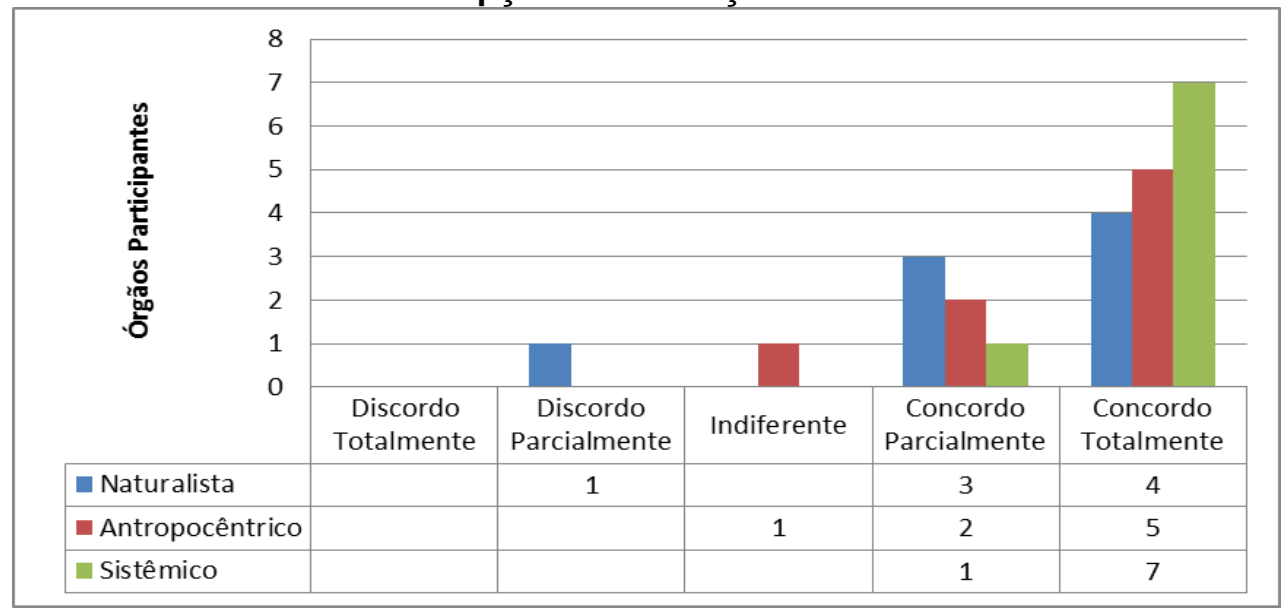

Fonte: Elaborada pelos autores com base nos dados coletados da pesquisa (2014).

O Gráfico 1 mostra que, em relação a concepção de educação ambiental, os colaboradores mostram ter uma visão mais sistêmica, em que o nível de concordância é maior para a definição sistêmica.

Foram escolhidas as definições naturalista, antropocêntrica e sistêmica, pois cada definição aborda as concepções de educação ambiental e meio ambiente partindo de diferentes pontos de vista. A definição naturalista tem a preservação da natureza como centro da definição, na antropocêntrica, a definição parte do homem, e por fim a Sistêmica relaciona todos os elementos que estão presentes no ambiente sistematicamente.

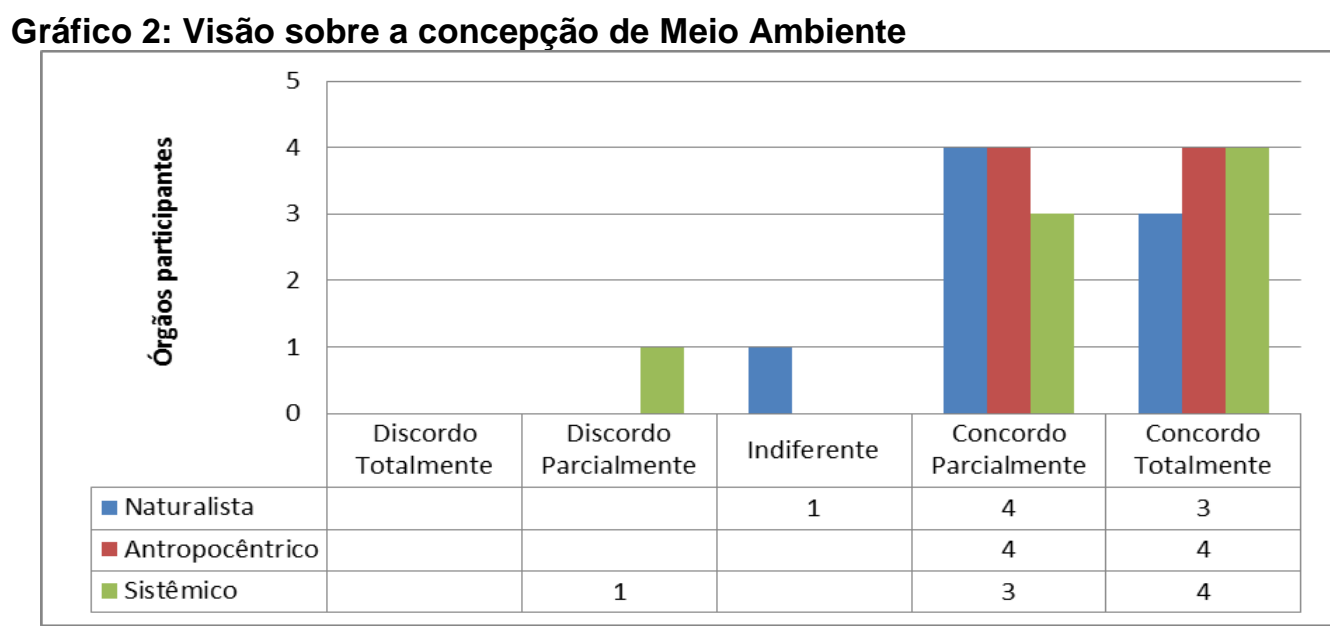

Fonte: Elaborada pelos autores com base nos dados coletados da pesquisa (2014). 
Por fim, o gráfico 2 mostra que a visão dos colaboradores, com relação ao meio ambiente, é uma visão mais antropocêntrica e sistêmica. Com isso, constata-se que por mais que das concepções de educação ambiental e meio ambiente estarem ligadas, as opiniões em relação as definições divergem um pouco.

No entanto, pode-se verificar que os órgãos públicos dos municípios de Adamantina e Dracena, desenvolvem ações, principalmente atividades, ainda que de curto prazo, e que essas atividades são voltadas para a população local, mas que impactam de certa forma na região da Bacia Hidrográfica Peixe-Aguapeí.

\section{CONSIDERAÇÕES FINAIS}

Diante dos resultados obtidos na pesquisa, foi possível identificar quais são os órgãos públicos que atuam na área de educação ambiental nos municípios de Adamantina e Dracena, e quais os tipos de ações que cada uma realiza.

Constatou-se que todos os órgãos públicos realizam atividades, projetos e programas voltados para as questões ambientais, ainda que de curto prazo, mas que não há um diálogo efetivo entre esses órgãos. No entanto, existe a realização de parcerias entre os órgãos e algumas empresas privadas nos municípios estudados.

Concluiu-se que os órgãos públicos estão de alguma forma tentando contribuir com a questão ambiental, no entanto, as atividades de educação ambiental, em sua maioria, ainda estão vinculadas a atividades pontuais, caracterizando-se mais como ações e práticas ambientais.

\section{REFERÊNCIAS}

BRASIL. Ministério do Meio Ambiente, Diretoria de Educação Ambiental; Ministério da Educação. Coordenação Geral de Educação Ambiental. Programa nacional de educação ambiental - ProNEA . 3. ed. Brasília : Ministério do Meio Ambiente, 2005.

Decreto- lei n. 9795, de 27 de abril de 1999. Dispões sobre a Educação ambiental e institui a Política Nacional de Educação Ambienta e dá outras providências. Diário Oficial da República Federativa do Brasil. Brasília, 1999.

Constituição 1988. Constituição da República Federativa do Brasil. São Paulo: Saraiva, 
CÂMARA MUNICIPAL DE DRACENA. História de Dracena. 2014. Disponível em: < http://www.camaradracena.sp.gov.br/index.php?pagina=curiosidade\&id=2>. Acesso em: 28 jan. 2014.

FARIA, M. A. B. MAZZARINO, J. M. OLIVEIRA, E. C. Educação Ambiental e Políticas Públicas. Revista eletrônica do Mestrado em Educação Ambiental. V. 30, n. 1, p. 179 - 201, jan./ jun. 2013. Disponível em: <http://www.seer.furg.br/remea/article/view/3232/2226>. Acesso em: 15 jan. 2014.

IBGE. Cidades. 2013. Disponível em: < http://cidades.ibge.gov.br/xtras/perfil.php?codmun=355500>. Acesso em: 28 dez. 2013.

LEFF, E. Saber ambiental: sustentabilidade, racionalidade, complexidade, poder. 4 ed. Petrópolis: Vozes, 2001.

MAZZA, A. Manual de Direito Administrativo. 3 ed. São Paulo: Saraiva, 2013.

RODRIGUES, F. Y. SANTANA, D. D. Administração pública: os poderes e deveres dos órgãos e agentes públicos. In: II Simpósio Nacional De Iniciação Científica. n. 20, 2012. Londrina. VI Prêmio de Produção Científica Prof. Ms. Reynaldo Camargo Neves 2012. Londrina. 2012.

PREFEITURA DE ADAMANTINA. História da Cidade. 2014. Disponível em: <http://www.adamantina.sp.gov.br/portal/hist-cidade.jsp>. Acesso em: 03 jan. 2014.

SAUVÉ, L. Educação Ambiental: Possibilidades e Limitações. São Paulo, Educação e Pesquisa, v. 31, n. 2, p. 317-322, maio/ago. 2005. Disponível em: <www.scielo.br/pdf/ep/v31n2/a12v31n2.pdf>. Acesso em: 17 fev. 2012.

SECRETARIA DO MEIO AMBIENTE. Manual de Orientações - PMVA. 2013. Disponível em: < http://www.ambiente.sp.gov.br/municipioverdeazul/files/2013/03/Manual_PMVA_2013.pdf>. Acesso em: 06 fev. 2014.

TRIVINOS, A. N. S. Introdução a pesquisa em Ciências Sociais: a pesquisa qualitativa em educação. São Paulo: Atlas, 1987. 175p. p. 91-115. 